\title{
Assessment of Potential Toxicological Effects of Cinnamon Bark Aqueous Extract in Rats
}

\author{
Rabiatul Adawiyah Ahmad ${ }^{1}$, Hamed Serati-Nouri ${ }^{2}$, Fadzilah Adibah Abdul Majid ${ }^{1}$, Mohamad \\ Roji Sarmidi ${ }^{3}$, Ramlan Abdul Aziz ${ }^{3}$ \\ ${ }^{1}$ Bioprocess Engineering Department, Faculty of Chemical Engineering, Universiti Teknologi Malaysia, \\ 81310 Johor Bahru, Johor, Malaysia. \\ ${ }^{2}$ Drug Applied Research Center, Tabriz University of Medical Sciences, Tabriz, Iran. \\ 3Institute of Bioproduct Development, Universiti Teknologi Malaysia, 81310 Johor bahru, Johor, Malaysia. \\ * Corresponding author. Tel: +989144001704, email: Seratinourih@tbzmed.ac.ir; adibah@cheme.utm.my. \\ Manuscript submitted August 28, 2014; accepted November 23, 2014. \\ doi: 10.17706/ijbbb.2015.5.1.36-44
}

\begin{abstract}
Cinnamon stick is world widely used in cooking, traditional medicine, perfumery and aesthetic industries. Many studies have demonstrated the potential of cinnamon extracts in diabetes treatment. Although it has been reported as safe in general cooking recipe and categorized as GRAS by USDA, sub-acute toxicity procedure was conducted in this study to determine the effect of cinnamon extract on histopathological changes as well as the haematological parameters of blood. Water extraction was done for dried cinnamon. Twenty-four female Sprague Dawley rats were used in this study. The oral route was selected because it is the most likely route of human exposure through the consumption of herbs. The concentrations studied were $0.1,0.5$ and $2.0 \mathrm{~g} / \mathrm{kg}$ cinnamon aqueous extract (CE). There were no statistically significant effects of all concentrations of CE on behaviour, mortality, water intake, food consumption, weight gain, internal organs weight (liver and kidney) and heamatological parameters during treatment and post-treatment periods except: 1) the slight decreased in kidney and liver weight of rats treated with $0.5 \mathrm{~g} / \mathrm{kg}$ and 2) slight decreased in liver weight of rats treated with $2.0 \mathrm{~g} / \mathrm{kg}$, during post-treatment period. Hence, these toxicity studies suggest that the CE is low to moderate in toxicity and CE below $0.5 \mathrm{~g} / \mathrm{kg}$ dose level is safe to be used in the efficacy study especially for diabetes treatment.
\end{abstract}

Key words: Aqueous extract, cinnamon, histopathology, haematology.

\section{Introduction}

Herbal medicine has enjoyed tremendous popularity worldwide. It has been used as an alternative road to wellness since antiquity even before the synthetic pharmaceutical drugs were introduced. However, there are others who regard herbal medicine with skepticism especially those in mainstream healthcare delivery systems. It is perceived as unsafe, under-developed and not well documented in addition to the possible side-effects and adverse reactions to the herbal medicines. Nonetheless, herbalists beg to differ. Traditional medicine now plays a greater role in modern medicine whereas a lot of readily available medicinal plants offer great potential for the discovery of new drugs while many others are yet to be unearthed [1]-[8].

Currently, there is a growing academic and industrial involvement in traditional medicine. In order to 
ensure that people will unequivocally embrace herbal medicine, researchers are executing thorough scientific investigations to provide evidences for its efficacy, safety and toxicity as well as the mechanisms of action. Plants are generally perceived to be safe, but there are plant materials which are hazardous to human being indicating the importance of toxicity study prior to human consumption [9]-[11].

Cinnamon is one of the must-have ingredients in our spice rack. Not only it possesses the unique characteristic as a flavouring agent, but also is famously known for its medicinal values. Barceloux (2009) shared several traditional uses of cinnamon, for instance as an astringent, germicide and antispasmodic [12]. According to Hwa et al., (2011), cinnamon was one of the foremost spices used in the early treatment for chronic bronchitis. In addition to that, other traditional practices for cinnamon include the treatment of impotence, frigidity, dyspnea, eye inflammation, rheumatism, vaginitis as well as wounds and toothaches [13].

Nowadays, numerous discoveries were made on cinnamon potential through modern research and cutting-edge technologies. Findings showed that cinnamon has significant activities as a hypoglycemic and cholesterol lowering agent [14] and mentioned polyphenolic polymer isolated from cinnamon to have insulin-like activity and antioxidant activity in vitro [15], [16]. Recent studies from Anand et al. (2010) found that in vitro incubation of cinnamon extract led to enhanced insulin release while Patel et al. (2012) listed cinnamon as an antidiabetic medicinal plant with insulin mimetic property [17], [18]. Apart from its antidiabetic property, it has shown to be promoting wound healing, antimicrobial agent, and anti-inflammatory compound [19]-[21].

Evidences exist, though very few, on safety concerns and toxicity of cinnamon consumption. Dugoua et al. (2007) reported that cinnamon is safe to be used in medicinal amounts but may be of concern when it is used in excessive amounts or in long term while Newal et al. (1996) specified that the amount of cinnamaldehyde consumption should not exceed $700 \mu \mathrm{g} / \mathrm{kg}$ [22]-[24]. Research conducted by Shah et al. (1998) stated that there was no significant acute and chronic mortality during their toxicity study on the ethanolic extract of Cinnamomumzeynalicum bark [22]. According to the United States Food and Drug Administration (USFDA), Cinnamomum spp., including common and cassia cinnamon are generally recognized as safe when used in amounts commonly found in food. Anderson (2008) also reported that there have been no adverse events accounted in all human studies involving cinnamon, or aqueous extracts of cinnamon [25].

Therefore, this study was undertaken to examine the possible toxicity effect of oral administration of the aqueous extract of cinnamon (CE) in rats in order to determine the $50 \%$ of lethal dose (LD50) value to be used as future references. Results of this study will enable us to project safety levels of cinnamon in animals and human. Sub-acute toxicity procedure was conducted in this study to determine the effect of cinnamon extract on haematological parameters of blood as well as the histopathological changes. The oral route was selected for toxicity studies because it is the most likely route of human exposure through the consumption of herbs.

\section{Materials and Methods}

\subsection{Chemicals}

Diethyl ether and hydrochloric acid were purchased from CheMar. Xylene, acetic acid, glycerol and ethanol were obtained from MERCK. Potassium acetae, Wright's stain and paraffin plasticized pellets were obtained from BDH. Formaldehyde was purchased from HmbG chemicals. Harris hematoxylin solution and eosin Y were purchased from Sigma-Aldrich.

\subsection{Plant Material and Preparation for Extract}


The plant material used in this study was the dried stem bark of cinnamon. The barks were purchased from Dru Era, Ceylon. Cinnamon bark was supplied by Nasuha Spices \& Herbs Farm near Johor, Malaysia (GPS Coordinates: GPS $1.940900 \mathrm{~N} 102.741300 \mathrm{E}$ ) using the standard management procedures for the species. Plant sample for voucher specimen was collected by author on Dec 122012 and was deposited to UTM Herbarium with voucher number UTM122009-1067. The cinnamon bark $(26.5 \mathrm{~kg})$ was then dried, grinded later extracted with $110 \mathrm{~L}$ of water $(1: 4)$ for $8 \mathrm{~h}$ at $120^{\circ} \mathrm{C}$ by turbo extractor through hydro distillation process. The water extract from the turbo extraction was proceeded to spray dried process to form powder. Dry yield was $2.09 \%(\mathrm{w} / \mathrm{w})$.

\subsection{Preparation of Experimental Animals}

Twenty-four female Sprague Dawley rats weighing 200-260g were used in this study. The animals were individually housed in cages under a 12-h light and 12-h dark cycle in a temperature controlled room $\left(25-27^{\circ} \mathrm{C}\right)$. Prior to the experiments, the rats were acclimated for a week and were allowed to free access of standard laboratory animal diet and water ad libitum.

\subsection{Experimental Design for Sub-acute Oral Toxicity Study (Repeated Dose 14 Days)}

The Fixed dose procedure was followed as described in OECD Guidelines 420 (2002) for oral toxicity study in order to determine the LD50. Groups of twenty-four female rats were divided into four groups which were fed with the following diet (Table 1):

Group Control: $\quad$ Normal rats received distilled water (control)

Group CE $0.1 \mathrm{~g} / \mathrm{kg}$ : Normal rats received $0.1 \mathrm{~g} / \mathrm{kg}$ powdered cinnamon extract (CE)

Group CE $0.5 \mathrm{~g} / \mathrm{kg}$ : Normal rats received $0.5 \mathrm{~g} / \mathrm{kg}$ powdered cinnamon extract (CE)

Group CE $2.0 \mathrm{~g} / \mathrm{kg}$ : Normal rats received $2.0 \mathrm{~g} / \mathrm{kg}$ powdered cinnamon extract (CE)

Treatment rats were treated once daily by oral administration using sterile ball-tipped gavages needle for 14 days respectively. Close observation was made during the first four hour to examine any adverse effect symptom such as abnormal behaviour, abnormal posture, diarrhea, blood in urine and increase in heart beat caused by CE consumption [26].

Food consumption, water intake and the body weight gained was recorded at day $0,3,7$ and 14 . Blood was withdrawn from tail vein by sterile needle on day 0,7 and 14 for hematology. Half of survived rats $(n=3)$ from each group were sacrificed on day 14 of sub-acute toxicity study to obtain liver and kidney for their relative weight (Table 1). Tissues for microscopic examination were fixed and preserved in $10 \%$ neutral

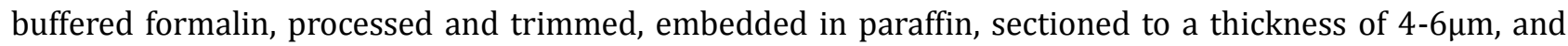
stained with hematoxylin and eosin. Complete histopathologic examinations were performed for any abnormalities and toxicological signs.

Table 1. Designated Group for Toxicity Study

\begin{tabular}{lllll}
\hline Day/Dose & Control & CE 0.1g/kg & CE 0.5g/kg & CE 2.0g/kg \\
\hline $\begin{array}{l}\text { Day 14 (sub-acute toxicity } \\
\text { study) }\end{array}$ & 3 rats & 3 rats & 3 rats & 3 rats \\
Day 28 (recovery period) & 3 rats & 3 rats & 3 rats & 3 rats \\
\hline \hline
\end{tabular}

\subsection{Experimental Design for Fourteen Days Recovery Period Study}

The Twenty- Half of the survived rats $(n=3)$ were returned back to their own cage and being kept for another 14 days for further observation (Table 1). During the period, all groups of rats were not treated with any CE extracts and were fed with food pellets and water ad libitum. Occurrence of toxicity symptom was observed twice daily. The animals were weighed at day 21 and 28 during recovery period. All rats were 
euthanized at day 28 to harvest liver and kidney for their relative weight. The organs were further analyzed via histological examination for any abnormalities.

\subsection{Statistical Analysis}

Data of body weight were evaluated using Sigma Plot 11.0. Values were expressed as means \pm SE. Statistical significance of treatments was determined using the Tukey's test. Food consumption, water intake and relative organ weight's data were evaluated using Sigma Plot 11.0. Values were expressed as means \pm SE. Dunnet's test was used to evaluate the results statistically. Data for differential white blood cell (WBC) count were performed using SPSS statistical version 15 . Values were expressed as means \pm SE. Non-parametric Mann-Whitney U-test was used to evaluate the results statistically.

\section{Results and Discussion}

\subsection{Survival Rates, Feed Consumption, Water Intake, Alterations in Body Weight and Relative Organ Weights}

There was neither any mortality nor abnormalities in general behaviour observed in all groups throughout the study. Therefore, the approximate LD of cinnamon aqueous extract in Sprague Dawley (SD) rats was higher than $2.0 \mathrm{~g} / \mathrm{kg}$. This result was in line with the study by Shah et al. (1998), showing no sign of toxicity in rats when low dosage of CE were administered [22].

In order to examine the development of secondary stage of toxicity caused by chemical analysis, parameters such as food consumption and water intake were considered. Changes in food consumption and water intake may relate to the alterations in body weight as well as in organ weight.

No significant differences were observed among all the four groups in food consumption during the 28 days experimental period (Fig. 1a). However, at day 7, groups treated with 0.1 and $2.0 \mathrm{~g} / \mathrm{kg}$ of CE showed lower food consumption than control group. These results were aligned with the body weight changes results, which showed significant lower in body weights of CE 0.1 and CE 2.0 groups compared to controls at 7 days of experimental period. It may be due to poor palatability of the feed. It is believed that CE did not play a role in food consumption alteration because they showed no dose-related effect.

The overall water consumption of animals receiving the CE extract was generally similar to that of the vehicle control. This result suggested that consumption of all CE dosages was not affecting the changes of water intake during the study period (Fig. 1b).

Changes in body and internal organ weights could be used as an indicator for unspecific adverse side effects. Generally, weight loss is a simple and sensitive index of toxicity after an exposure to toxic substance [27], [28]. From (Fig. 1c.), the result showed no significant difference in the body weight changes for all groups throughout the study. Hence, it indicated that the comparable amounts of CE consumed within the experimental period did not cause toxicity.

Relative liver and kidney weights of the experimental rats were calculated based on Abdullah et al. (2009) method and are presented in (Fig. 2a and b) [29]. No statistical differences were observed between the relative organ weight of liver and kidney in the orally treated groups compared to the control group during 14-day sub-acute toxicity study (Fig. $2 \mathrm{a}$ and b). The oral administration of $0.5 \mathrm{~g} / \mathrm{kg}$ CE significantly decreased the relative liver and kidney weights compared to control group after fourteen days recovery period (Fig. 2a and b). This result was similar with the work done by Shah et al. (1998), where C. zeylanicum treatment caused reduction in the relative liver weight [22]. Besides, the rats fed with $2.0 \mathrm{~g} / \mathrm{kg}$ of CE showed a significant decrease in relative kidney weight as compared to control group but not in relative liver weight (Fig. 2a and b). 
(a)

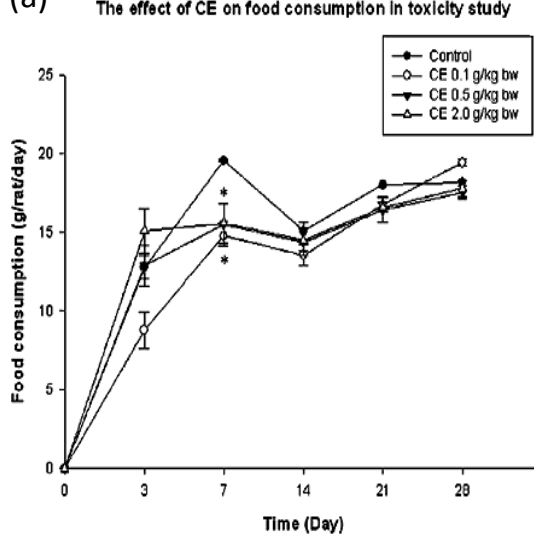

(b)

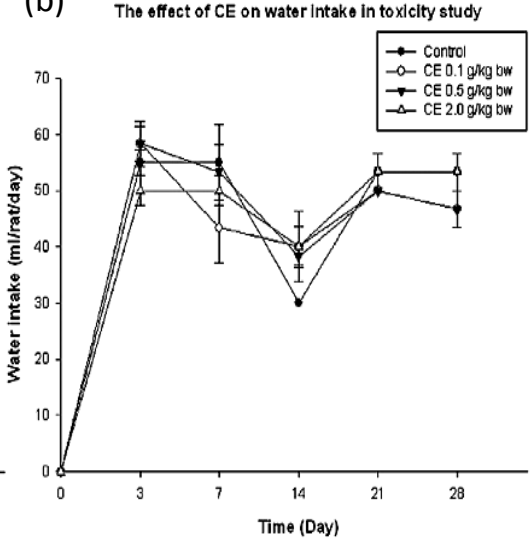

(c)

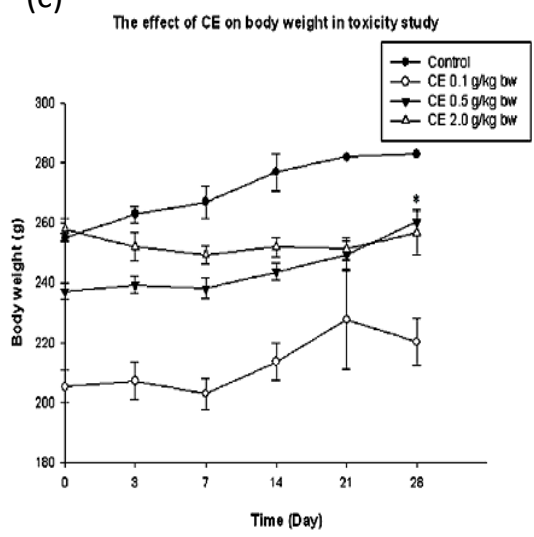

Fig. 1. (a) The effect of CE on food consumption in normal rats. (b) The effect of CE on water intake in normal rats. (c) The effect of CE on body weight in normal rats.

The effect of CE on relative kidney weights in toxicity study

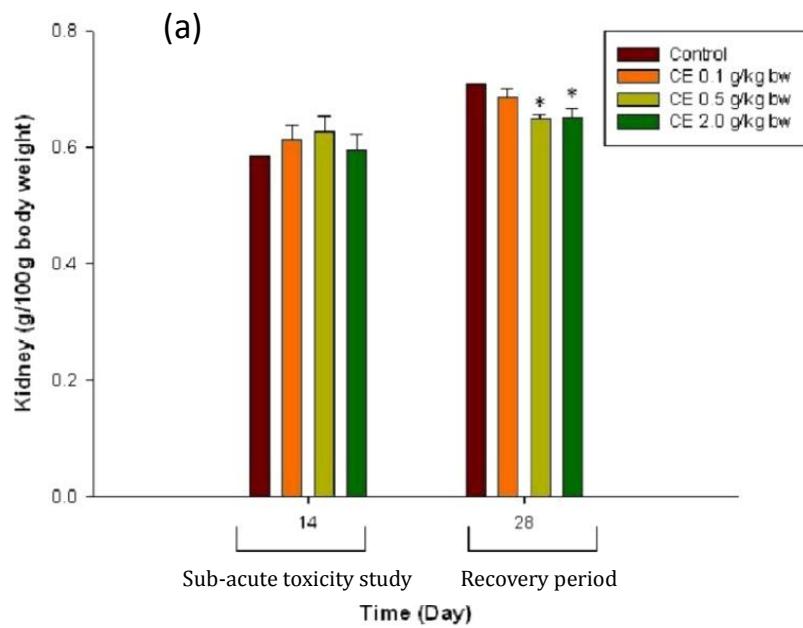

The effect of $C E$ on relative liver weights in toxicity study

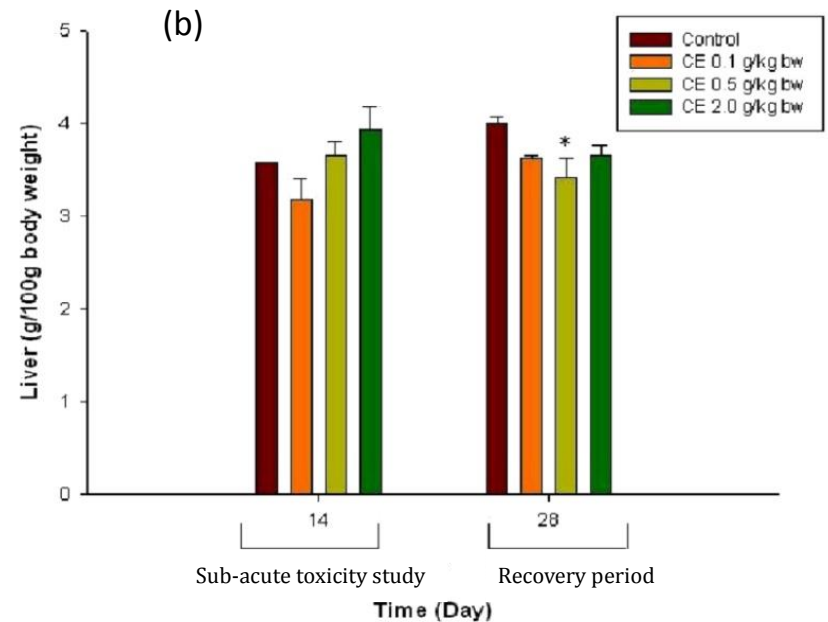

Fig. 2. The effect of CE on relative organ weight in normal rats in sub-acute toxicity study and recovery period. (a) Relative kidney weights in each group. (b) Relative liver weights in each group.

\subsection{Haematological Examination}

The effects of repeated-dose oral administration of the CE on the differential white blood cells (WBC) count parameters were presented in Fig. 3. The differences in the values of differential WBC count parameters between the control group and the experimental rats were statistically insignificant. Thus, this result did not appear to be related to the treatment with CE because they showed no dose-response relationship.

\subsection{Histological Examinations}

Histopathological changes in liver and kidney of the control and experimental rats during 14 days sub-acute toxicity study as well as fourteen days recovery period were compiled in below (Fig. 4). However, since diethyl ether was used in this study to euthanize the animals, its application may have affected the findings.

Fig. 4a revealed no apparent changes in the morphological structure of the liver in normal rats since 
significant changes occurred after administration of cinnamon aqueous extract (CE).Thrombusin the sinusoidal liver tissue of rat treated with $0.1 \mathrm{~g} / \mathrm{kg} \mathrm{CE}$ indicated the presence of toxic substances though other parts of the liver tissue were normal (Fig. 4b). Fig. 4c showed sinusoids were more experienced thrombosis in rat's liver tissue treated with $0.5 \mathrm{~g} / \mathrm{kg}$ CE. Moreover, nucleuses of the hepatocytes began to lose chromatin. From Fig. 4d., fibrinous material in the endothelium of portal vein showed that injuries were caused by toxic substances. Thrombus formation began to occur in the portal vein itself and the sinusoid cells started to show a presence of fibrinous material. However, no fatty liver had occurred.

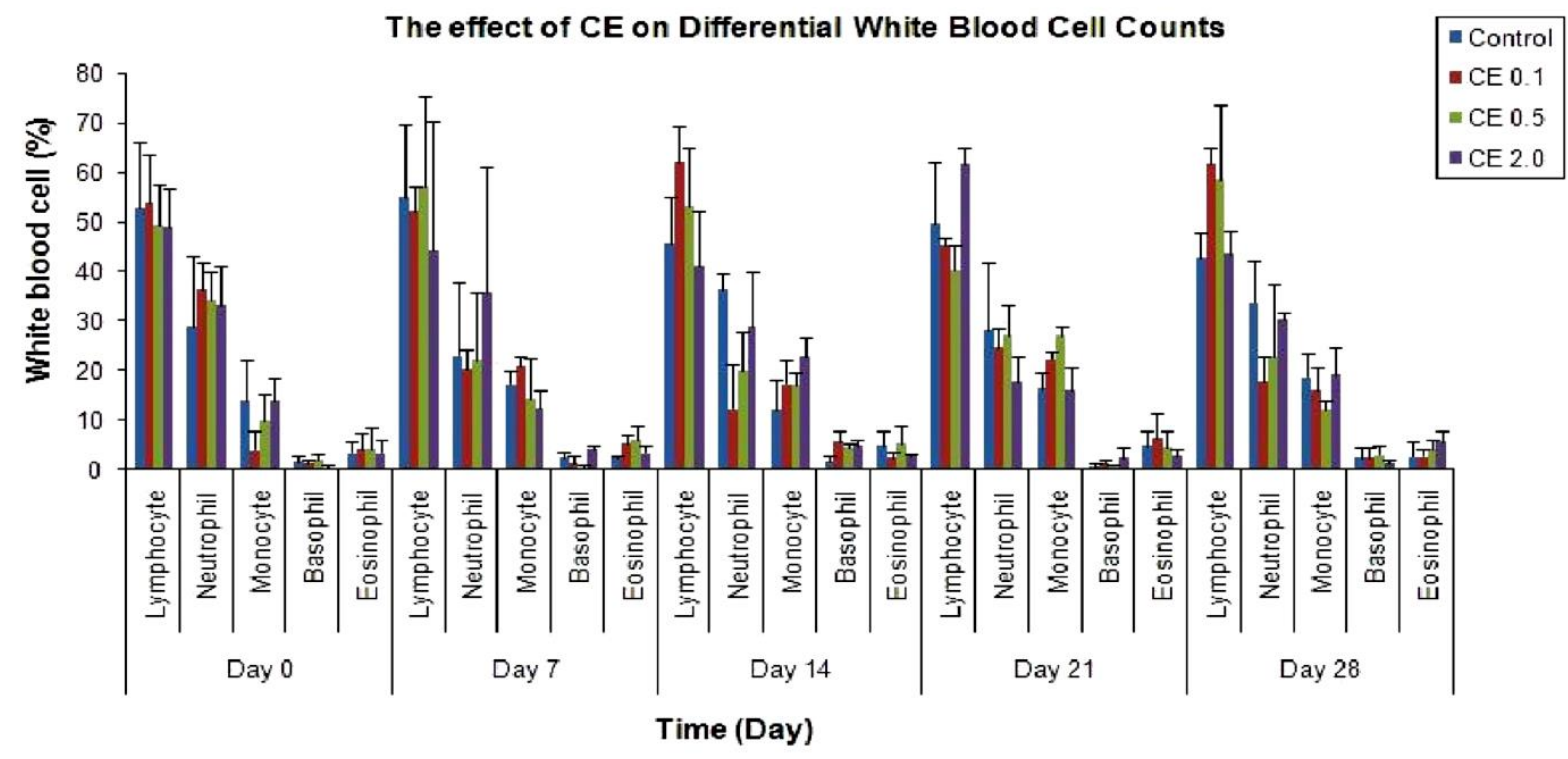

Fig. 3. The effect of CE on differential count of white blood cell in normal rats.

Fig. 4e showed that hepatocytes began to lose their nucleus in control rats. This was a symptom of fatty liver in which the nucleus was pushed to the peripheral and lost. Swelling of hepatocytes and presence of fibrinous material and thrombus were clearly shown in the liver tissue of rats treated with $0.1 \mathrm{~g} / \mathrm{kg}$ CE (Fig. 4f). In addition, Fig. 4g exhibited a clear fibrinous material of sinusoids and swelling of hepatocytes with exception of the thrombus presence while in rats treated with $2.0 \mathrm{~g} / \mathrm{kg} \mathrm{CE}$, the situation was more serious because of fibrinous material met the hepatic portal vein lumen and sinusoidal (Fig. 4h).

Fig. $4 \mathrm{i}$ to $4 \mathrm{p}$ showed the histopathological changes in the kidney of control and experimental rats after 14-day sub-acute toxicity study along with the findings for fourteen days recovery period. Fig. 4i illustrated normal architecture of kidney of the control rats. Bowman capsules space narrowing indicated swelling of the glomelurus in the rat administered with of $0.1 \mathrm{~g} / \mathrm{kg}$ CE. Convoluted proximal tubules also showed that cells were having hyperthrophy (Fig. 4j). Fig. 4k showed thrombus presence in the small blood vessels that supplied nephron tissues in the kidney section of the rat given $0.5 \mathrm{~g} / \mathrm{kg}$ CE. The cells lining on proximal and distal convoluted tubules were experiencing hyperthropy. Besides, glomerulus had fibrinous materials which showed sensitivity towards toxic substances in the rats supplemented with $2.0 \mathrm{~g} / \mathrm{kg} \mathrm{CE}$ (Fig. 4l).

Fig. $4 \mathrm{~m}$ illustrated normal appearance of kidney from control rats. Fibrinous materials can be observed in the proximal convoluted tubules and hyperthropy of the cells lining the tubules in kidney tissue of the rat treated with $0.1 \mathrm{~g} / \mathrm{kg} \mathrm{CE}$ (Fig. $4 \mathrm{n}$ ). Mild fibrinous materials were observed in the glomerulus area of rats treated with $0.5 \mathrm{~g} / \mathrm{kg}$ CE (Fig. 4o). Early development of glomerulonephritis was spotted in kidney of rats treated with $2.0 \mathrm{~g} / \mathrm{kg} \mathrm{CE}$ (Fig. $4 \mathrm{p}$ ).

Thus, these results revealed serious signs of toxicity in the liver and kidney of the rats treated with 2.0 
$\mathrm{g} / \mathrm{kg}$ CE. Although pathological changes were observed in liver and kidney of the rats supplemented with 0.1 and $0.5 \mathrm{~g} / \mathrm{kg}$ of $\mathrm{CE}$, there were no relevance of serious signs in the histopathological examination. In consequence, these results suggested that administration of CE below $0.5 \mathrm{~g} / \mathrm{kg}$ dose level is safer to be employed for further study.

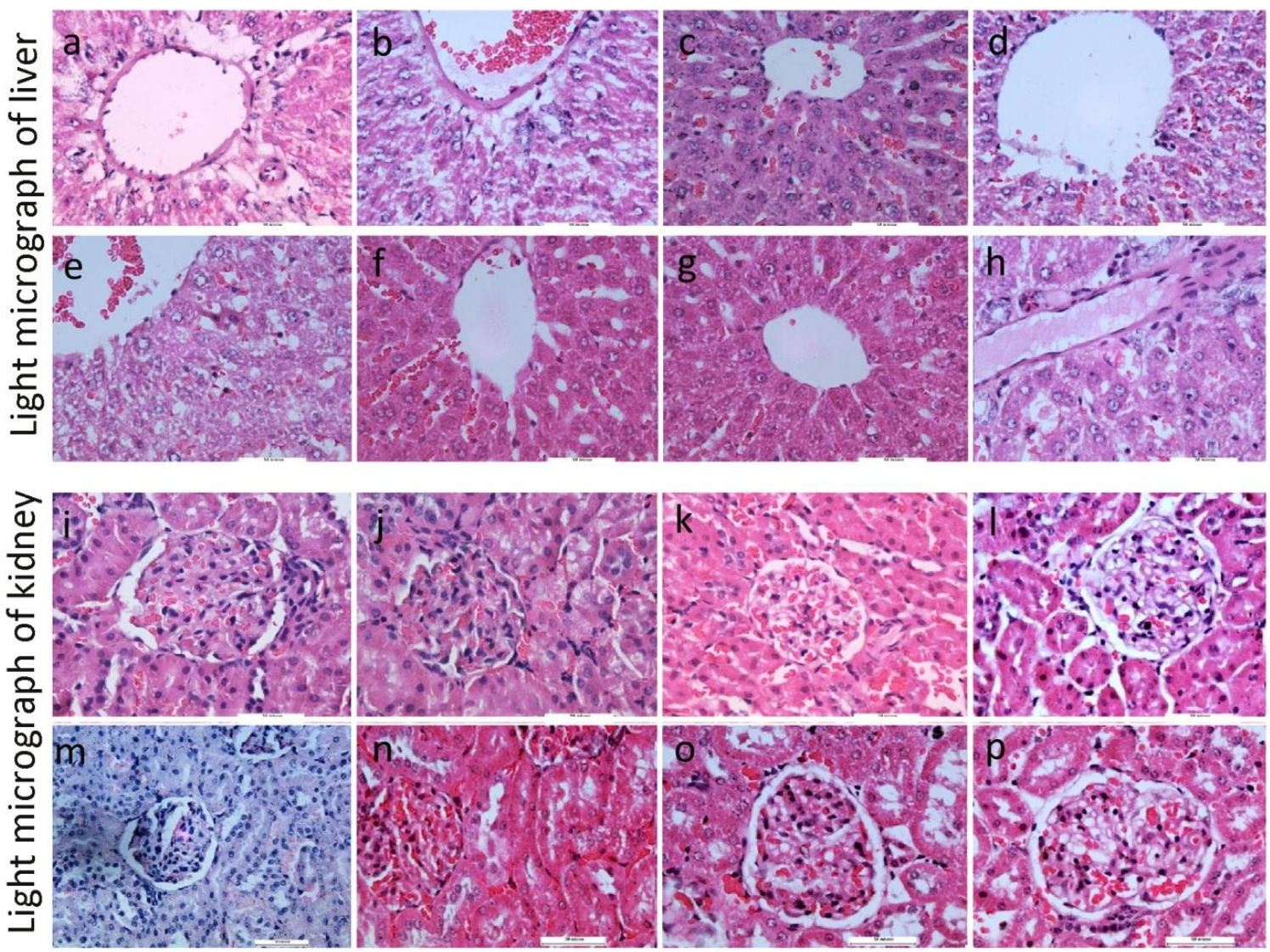

Fig. 4. Light micrograph of liver and kidney during 14 days sub-acute toxicity study.

\section{Conclusion}

Haematological and histopathological data of rats fed with cinnamon bark aqueous extract were evaluated in this acute oral toxicity studies to select suitable starting dose for human phase I study. These toxicity studies suggest that the CE is low to moderate in toxicity, evidenced by high LD50 values with no lethality. The CE below $0.5 \mathrm{~g} / \mathrm{kg}$ dose level is safer to be used in the efficacy study. With the low toxicity of the CE, it offers a wide margin of safety for beneficial doses. Nevertheless, further in-depth toxicity studies are needed to confirm the findings. In this respect, the present work provides some indications at what doses further efficacy studies can be conducted.

\section{Acknowledgment}

This research was supported by the grant from Ministry of Science, Technology and Innovation (MOSTI) of Malaysia and Biosatellite Johor Project.

\section{References}

[1] Liu, L. Y., Feng, B., Chen, J., Tan, Q. R., Chen, Z. X., Chen, W. S., et al. (2015). Herbal medicine for hospitalized patients with severe depressive episode: A retrospective controlled study. Journal of 
Affective Disorders, 170(0), 71-77.

[2] Hajiaghaalipour, F., Kanthimathi, M. S., Sanusi, J., \& Rajarajeswaran, J. (2015). White tea (Camellia sinensis) inhibits proliferation of the colon cancer cell line, HT-29, activates caspases and protects DNA of normal cells against oxidative damage. Food Chemistry, 169(0), 401-410.

[3] Zielińska-Pisklak, M. A., Kaliszewska, D., Stolarczyk, M., \& Kiss, A. K. (2015). Activity-guided isolation, identification and quantification of biologically active isomeric compounds from folk medicinal plant Desmodium adscendens using high performance liquid chromatography with diode array detector, mass spectrometry and multidimentional nuclear magnetic resonance spectroscopy. Journal of Pharmaceutical and Biomedical Analysis, 102(0), 54-63.

[4] Ezzati Nazhad Dolatabadi, J., Mokhtarzadeh, A., Ghareghoran, S. M., \& Dehghan, G. (2014). Synthesis, characterization and antioxidant property of quercetin-Tb(III) complex. Advanced Pharmaceutical Bulletin, 4(2), 101-104.

[5] Jamali, A., Tavakoli, A., \& Ezzati Nazhad Dolatabadi, J. (2012). Analytical overview of DNA interaction with Morin and its metal complexes. Eur. Food Res. Technol., 235(3), 367-373.

[6] Ahmadi, S. M., Dehghan, G., Hosseinpourfeizi, M. A., Dolatabadi, J. E., \& Kashanian, S. (2011). Preparation, characterization, and DNA binding studies of water-soluble quercetin--molybdenum(VI) complex. DNA and Cell Biology, 30(7), 517-523.

[7] Dehghan, G., Dolatabadi, J. E. N., Jouyban, A., Zeynali, K. A., Ahmadi, S. M., \& Kashanian, S. (2011). Spectroscopic studies on the interaction of quercetin-terbium (III) complex with calf thymus DNA. DNA and Cell Biology, 30(3), 195-201.

[8] Ajlia, S. A., Majid, F. A., Suvik, A., Effendy, M. A., \& Nouri, H. S. (2010). Efficacy of papain-based wound cleanser in promoting wound regeneration. Pakistan Journal of Biological Sciences, 13(12), 596-603.

[9] Domijan, A. M., Gajski, G., Novak Jovanović, I., Gerić, M., \& Garaj-Vrhovac, V. (2015). In vitro genotoxicity of mycotoxins ochratoxin A and fumonisin B1 could be prevented by sodium copper chlorophyllin Implication to their genotoxic mechanism. Food Chemistry, 170(0), 455-462.

[10] Ahmad, R. A., Abdullah, S. H. A. S., Serati-Nouri, H., Majid, F. A. A., Sarmidi, M. R., \& Aziz, R. A. (2014). Antiproliferative activity of coumarin and cinnamon water extracts on human ovarian cancer cells. Latin American Journal of Pharmacy, 33(6), 960-965.

[11] Dolatabadi, J. E. N. (2011). Molecular aspects on the interaction of quercetin and its metal complexes with DNA. International Journal of Biological Macromolecules, 48(2), 227-233.

[12] Barceloux, D. G. (2009). Cinnamon (Cinnamomum species). Disease-a-month : DM, 55(6), 327-335.

[13] Hwa, J. S., Jin, Y. C., Lee, Y. S., Ko, Y. S., Kim, Y. M., Shi, L. Y., et al. (2011). 2-Methoxycinnamaldehyde from Cinnamomum cassia reduces rat myocardial ischemia and reperfusion injury in vivo due to HO-1 induction. Journal of Ethnopharmacology, 139(2), 605-615.

[14] Khan, A., Safdar, M., Ali Khan, M. M., Khattak, K. N., \& Anderson, R. A. (2003). Cinnamon improves glucose and lipids of people with type 2 diabetes. Diabetes Care, 26(12), 3215-3218.

[15] Anderson, R. A., Broadhurst, C. L., Polansky, M. M., Schmidt, W. F., Khan, A., Flanagan, V. P., et al. (2003). Isolation and characterization of polyphenol type-A polymers from cinnamon with insulin-like biological activity. Journal of Agricultural and Food Chemistry, 52(1), 65-70.

[16] Taher, M., Fadzilah, A. A. M., \& Mohomad, R. S. (2006). A proanthocyanidin from Cinnamomum zeylanicum stimulates phosphorylation of insulin receptor in 3T3-L1 adipocytes. Jurnal Teknologi, 44, 53-68.

[17] Anand, P., Murali, K. Y., Tandon, V., Murthy, P. S., \& Chandra, R. (2010). Insulinotropic effect of cinnamaldehyde on transcriptional regulation of pyruvate kinase, phosphoenolpyruvate carboxykinase, and GLUT4 translocation in experimental diabetic rats. Chemico-Biological Interactions, 186(1), 72-81.

[18] Patel, D. K., Prasad, S. K., Kumar, R., \& Hemalatha, S. (2012). An overview on antidiabetic medicinal plants having insulin mimetic property. Asian Pacific Journal of Tropical Biomedicine, 2(4), 320-330.

[19] Cao, H., Urban, J. F. Jr., \& Anderson, R. A. (2008). Cinnamon polyphenol extract affects immune responses by 
regulating anti- and proinflammatory and glucose transporter gene expression in mouse macrophages. Journal of Nutrition, 138(5), 833-840.

[20] Farahpour, M. R., \& Habibi, M. (2012). Evaluation of the wound healing activity of an ethanolic extract of Ceylon cinnamon in mice. Veterinarni Medicina, 57(1), 53-57.

[21] Yang, J., Kuang, X., Li, B., Zhou, B., Li, J., Cui, B., \& Ma, M. (2012). Study on release mechanisim of inhibitory components from cinnamon and clove powders. Journal of Food Safety, 32(2), 189-197.

[22] Shah, A. H., Al-Shareef, A. H., Ageel, A. M., \& Qureshi, S. (1998). Toxicity studies in mice of common spices, Cinnamomum zeylanicum bark and Piper longum fruits. Plant Foods for Human Nutrition (Formerly Qualitas Plantarum), 52(3), 231-239.

[23] Newall, C. A., Anderson, L. A., \& Philpson, J. D. (1996). Herbal medicine: A Guide for Healthcare Professionals. London UK: The Pharmaceutical Press.

[24] Dugoua, J. J., Seely, D., Perri, D., Cooley, K., Forelli, T., Mills, E., et al. (2007). From type 2 diabetes to antioxidant activity: A systematic review of the safety and efficacy of common and cassia cinnamon bark. Canadian Journal of Physiology and Pharmacology, 85(9), 837-847.

[25] Anderson, R. A. (2008). Chromium and polyphenols from cinnamon improve insulin sensitivity. Proceedings of the Nutrition Society, 67(01), 48-53.

[26] Tuffery, A. A. (1995). Laboratory animals: An introduction for experiment. 2nd ed. New York: John Wiley \&Sons.

[27] Raza, M., Al-Shabanah, O. A., El-Hadiyah, T. M., \& Al-Majed, A. A. (2002). Effect of prolonged vigabatrin treatment on hematological and biochemical parameters in plasma, liver and kidney of Swiss albino mice. Scientia Pharmaceutica, 70, 135-145.

[28] Teo, S., Stirling, D., Thomas, S., Hoberman, A., Kiorpes, A., \& Khetani, V. (2002). A 90-day oral gavage toxicity study of D-methylphenidate and D, L-methylphenidate in Sprague-Dawley rats. Toxicology, 179(3), 183-196.

[29] Abdullah, N. R., Ismail, Z., Ismail, Z. (2009). Acute toxicity of Orthosiphon stamineus Benth standardized extract in Sprague Dawley rats. Phytomedicine, 16, 222-226.

Rabiatul Adawiyah Ahmad received her B.Sc. in chemical engineering at Universiti Teknologi Malaysia. She is presently a M.Sc student at Universiti Teknologi Malaysia.

Hamed Serati-Nouri was born at Tabriz, Iran on April 29, 1981. He received his veterinary doctorate degree (DVM) from Islamic Azad University of Tabriz, Iran in December 2006. He is presently a PhD student at Tabriz University of Medical Sciences (Iran) and following his research projects at Drug Applied Research Center on pharmacological sciences. He is currently a member of ASPET, ASA \& ESHRE. So far, he has published several papers in the field of pharmacology, andrology, and phytotherapy.

Fadzilah Adibah Abdul Majid received her B.Sc. in biotechnology from University of Leeds, UK and obtained her $\mathrm{PhD}$ in chemical engineering from Birmingham, UK. She is currently an associate professor and the head of Bioprocess Engineering Department at Universiti Teknologi Malaysia.

Mohamad Roji Sarmidi received his B.Sc. in chemical engineering from University of Surrey, U.K and obtained his $\mathrm{PhD}$ in the same subject from Aston University, U.K. He is currently a professor of bioprocess engineering at Universiti Teknologi Malaysia.

Ramlan Abdul Aziz received both his B.Sc. in chemical engineering as well as his M.Sc. from the University of Manchester Institute of Science and Technology in chemical engineering. He is currently a director of Institute of Bioproduct Development since 2011 at Universiti Teknologi Malaysia. 